\title{
Advanced oxidation/reduction technologies: a perspective from Iberoamerican countries
}

\author{
Vítor J.P. Vilar ${ }^{1}$ - Elisama V. Dos Santos ${ }^{2}$ - Carlos A. Martínez-Huitle ${ }^{2}$ \\ Published online: 19 April 2021 \\ (C) The Author(s), under exclusive licence to Springer-Verlag GmbH Germany, part of Springer Nature 2021
}

The increasing global health concerns due to the surge in urbanization, increasing water contamination, and increasing world industrialization are driving advanced oxidation technologies (AOTs) market globally.

This special issue of Environmental Science and Pollution Research contains a selection of 51 papers presented at the $4^{\text {th }}$ Iberoamerican Conference on Advanced Oxidation Technologies (IV-CIPOA), which was chaired by Dr. Vítor Vilar, Prof. Dr. Carlos A. Martínez-Huitle, and Prof. Dr. Elisama Vieira dos Santos held in Natal City, Brazil, from 18 to 22 November 2019.

The history of CIPOA started in the year 2013. Since then the meetings have been held every 2 years. The first meeting was held in Recife (Brazil), the second in Belo Horizonte (Brazil), and later in Guatapé (Colombia) and Natal (Brazil). The number of participants has been around 200, reaching a maximum of 230 participants in Belo Horizonte.

The conference program included 12 plenary lectures, 84 regular oral presentations, 36 short oral communications, and 215 poster contributions, in the field of ozonation, advanced oxidation processes (AOPs), electrochemical advanced

Responsible Editor: Philippe Garrigues

Vítor J.P. Vilar

vilar@fe.up.pt

Elisama V. Dos Santos

elisamavieira@ect.ufrn.br

Carlos A. Martínez-Huitle

carlosmh@quimica.ufrn.br

1 Laboratory of Separation and Reaction Engineering-Laboratory of Catalysis and Materials (LSRE-LCM), Departamento de Engenharia Química, Faculdade de Engenharia da Universidade do Porto, Rua Dr. Roberto Frias, 4200-465 Porto, Portugal

2 Laboratório de Eletroquímica Ambiental e Aplicada, Instituto de Química, Universidade Federal do Rio Grande do Norte, Lagoa Nova, RN CEP 59.072-900, Brazil oxidation processes (EAOPs), and their integration with other physical/chemical and biological processes.

The present collection includes articles dealing with (i) non-photochemical AOPs in homogeneous phase (ozonation, ozonation with hydrogen peroxide, Fenton, electro-oxidation, electro-Fenton, etc.); (ii) photochemical AOPs in homogeneous phase (ionizing radiation, $\mathrm{UV} / \mathrm{H}_{2} \mathrm{O}_{2}, \mathrm{UV} /$ persulfate, $\mathrm{UV} / \mathrm{O}_{3}, \mathrm{UV} / \mathrm{O}_{3} / \mathrm{H}_{2} \mathrm{O}_{2}$, photo-Fenton, electro-photo-Fenton;, etc.); (iii) non-photochemical AOPs in heterogeneous phase (catalytic ozonation, electrocatalysis, etc.); (iv) photochemical AOPs in heterogeneous phase (photocatalytic ozonation, photocatalysis, photoelectrocatalysis, etc.); (v) integration of AOTs with coagulation/flocculation, biological oxidation, adsorption, etc.; (vi) contactors/photoreactors configurations (bubble columns, tubular photoreactors, solar collectors, etc.); (vii) AOTs applied to the treatment of contaminated soil, water, and air; and (viii) photocatalysis for $\mathrm{CO}_{2}$ reduction into valuable fuels.

The guest editors would like to thank all the authors for the innovative scientific contributions to this special issue and the reviewers whose comments and suggestions were extremely important to achieve high-quality papers, as well as the institutions and companies that sponsored the IV-CIPOA meeting.

We also thank ESPR Editor-in-Chief Philippe Garrigues and the editorial assistants Fanny Creusot and Carmina Joy Cayago for their assistance/help/support in the preparation of this special issue.

Vítor J.P. Vilar wishes to thank the FCT Individual Call to Scientific Employment Stimulus 2017 (CEECIND/01317/ 2017) and the financial resources provided by Associate Laboratory LSRE-LCM - UIDB/50020/2020 - funded by national funds through FCT/MCTES (PIDDAC). Financial supports from the Conselho Nacional de Desenvolvimento Científico e Tecnológico (CNPq-306323/2018-4, CNPq312595/2019-0; CNPq-439344/2018-2) and from Fundação de Amparo à Pesquisa do Estado de São Paulo (Brazil) (FAPESP 2014/50945-4 and 2019/13113-4) are gratefully 
acknowledged by Elisama V. Dos Santos and Carlos A. Martínez-Huitle.

Author contribution The statement to specify the contribution of each co-author is as follows:

- Analyzed the data: Vítor J.P. Vilar, Elisama V. Dos Santos, Carlos A. Martínez-Huitle

- Contributed funding: Vítor J.P. Vilar, Elisama V. Dos Santos, Carlos A. Martínez-Huitle

- Drafted or revised the manuscript: Vítor J.P. Vilar, Elisama V. Dos Santos, Carlos A. Martínez-Huitle

Data availability All data generated or analyzed during this study are included in this article.

Declarations All the authors approved the manuscript and this submission. This manuscript describes an original work, which has not been published before and is not under consideration by any other journal.

Ethics approval and consent to participate Not applicable.

Consent for publication Not applicable.

Competing interests The authors declare no competing interests.

Publisher's note Springer Nature remains neutral with regard to jurisdictional claims in published maps and institutional affiliations.

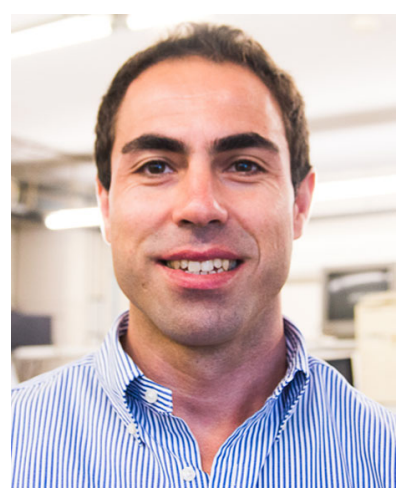

Vítor J.P. Vilar is principal researcher in the Laboratory of Separation and Reaction Engineering-Laboratory of Catalysis and Materials (LSRELCM), Faculty of Engineering of the University of Porto (FEUP), Porto, Portugal. He earned his BSc (2001) and $\mathrm{PhD}$ (2006) in Chemical Engineering from FEUP. In 2015, he received a "Special Visiting Researcher" grant in the Federal University of Santa Catarina, Brazil. From 2016 to 2020 , he served as Associate Editor of Environmental Science and Pollution Research Journal Springer. He is currently Associate Editor of Journal of Environmental Chemical Engineering - Elsevier. He was Special Issue Guest Editor of the Chemical Engineering Journal (Elsevier), Journal of Hazardous Materials (Elsevier), and Science of the Total Environment (Elsevier). $\mathrm{He}$ is a member of the Environmental Biotechnology Division of the European Federation of Biotechnology, a member of the scientific committee of the International Ph.D. School on AOPs, and coordinator of the
Iberoamerican Conference on Advanced Oxidation Technologies (CIPOA). He has expertise on environmental assessment and monitoring of surface waters, environmental remediation technologies (biological oxidation, coagulation/flocculation, adsorption/biosorption, ion exchange, advanced oxidation processes, electrochemical advanced oxidation processes, ozonation, and membrane filtration), wastewater resources recovery, and process integration and intensification. He also provides advisory services to public institutions and environmental and water industry. He has more than 500 scientific publications, including 220 ISI papers (h-index of $46,>7300$ citations) and 2 patents. He is among the $2 \%$ world-ranking scientists (PLoS) in the field of chemical engineering. He is deeply committed to moving research beyond specialist journals so as to change industry and environmental practice.

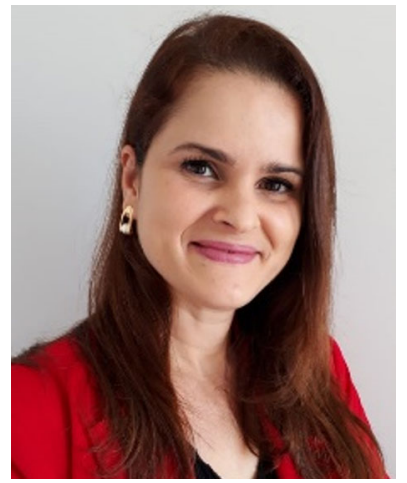

Elisama Vieira dos Santos (Santa Cruz, Brazil) obtained her $\mathrm{PhD}$ in Chemistry (2015) at the Federal University of Rio Grande do Norte (UFRN). She has conducted a research experience in the Electrochemical \& Environmental Engineering Lab at the Universidad de Castilla La-Mancha (Spain, 2014) under the supervision of Prof. Manuel Andres Rodrigo, evaluating pesticide decontamination of wastewaters and soils by using electrochemical oxidation and electrokinetic remediation, respectively. In 2016, she joined at the UFRN as Associate Professor in Chemistry. Her research mainly focuses on electrokinetic remediation, and electrochemical advanced oxidation processes (electrochemical remediation, photo-electrolysis, renewable energydriven electrochemical technologies) as well as the construction of electrochemical sensors and electroanalytical techniques for detecting heavy metals and organic compounds in real samples. She is author and coauthor of more than 90 scientific publications, including 2 conference books, 06 book chapters, 01 book, 55 papers in peer-reviewed international scientific journals (h-index of 18), 2 papers in national scientific periodicals, more than 40 contributions in conference proceedings, and a co-inventor of 1 patent, receiving 4 prizes in total. She participated in different sponsored projects ( 01 international, 05 national, and 02 contracts with private companies). She has mentored 06 Master students, 04 Ph.D. students, and 02 Postdoctoral researchers. In 2016, she was awarded by UNESCO and the L'Oréal Foundation with the important prize "Women in Science," regarding her relevant scientific contributions and developments on environmental protection. In 2020, she was awarded with the Prize on Environmental Electrochemistry by the International Society of Electrochemistry. She has participated as a committee member in international conferences on environmental electrochemistry and engineering, delivering 20 plenary/keynote/invited lectures at international conferences and scientific institutions. She is currently associate editor on Química Nova journal (Brazilian Chemical Society) and coordinator of the Postgraduate Program in Chemical Engineering at UFRN. 


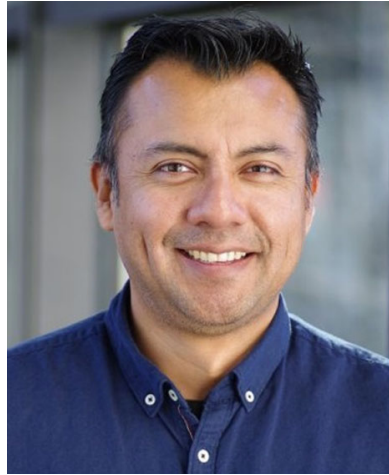

Prof. Carlos A. Martínez-Huitle He graduated in Chemistry at Universidad de las AméricasPuebla (México) under supervision of Prof. Marco Antonio Quiroz Alfaro. After a work experience in Ciba-Specialty Chemicals (currently, BASF), he moved to Ferrara (Italy) where he received his $\mathrm{PhD}$ in Chemical Sciences at the University of Ferrara under supervision of Prof. Achille De Battisti. During the same period, he worked as visiting scientist in the group of Prof. Christos Comninellis at the EPFL Institute, Switzerland. From 2005 to 2008, he has served as a faculty member in the Department of Chemistry at the University of Milan. In 2008, he also moved to Brazil where he currently is a Full Professor in the Institute of Chemistry at the Federal University of Rio Grande do Norte. He was awarded with the "Oronzio and Niccolò De Nora Foundation Prize" by the Italian Chemical Society (2005) and the "Oronzio and Niccolò De Nora Foundation Prize on Environmental Electrochemistry" by the International Society of Electrochemistry (2009). He was also recognized by German Government with the "Green Talent Award" for his contributions in the field of electrochemical water disinfection treatment. He is author and coauthor of more than 400 scientific publications, including conference books, book chapters, books, 250 papers in peer-reviewed international scientific journals (h-index of 46, > 10,700 citations), papers in national scientific journals, more than 80 contributions in conference proceedings, and a co-inventor of 4 patents. He is co-editor of the books entitled "Synthetic Diamond Films" (Wiley \& Sons) and "Electrochemical Water and Wastewater Treatment" (Elsevier). He is an editorial member of several journals and an Associate Editor in Scientific Reports (Nature). His research interests include electrochemical advanced oxidation processes for water treatment, electrocatalytic materials, electrocatalysis, photoelectrocatalysis, electroorganic synthesis, and electroanalysis as well as the construction of electrochemical sensors and waste valorization. He participated as general chair of organizing committee of the XXI SIBEE (2017) and IV CIPOA (2019), Brazil; and he will be the ELO.WatR general chair, 2022. Currently, he is a member of different international environmental societies, the President of the Brazilian Society of Electrochemistry and Electroanalysis, Chair Elect of ISE Division 5, and a visiting scientist in the Institut für Organische Chemie at the Johannes Gutenberg-Universität Mainz (Germany) supported by Alexander von Humboldt Foundation. 